leucocyte ascorbic acid level within the normal range; after operation $66 \%$ achieved normal status. This improvement in ascorbic acid nutrition, however, did not correlate well with the improvement in dietary intake, and only when one considered those in whom both dietary and leucocyte ascorbic acid levels were subnormal before operation did this correlation achieve significance (Fig. 2). This paradox may be explained on the grounds that, whereas the leucocyte ascorbic acid estimations were accurate, the dietary ascorbic acid levels were of necessity only approximations, which lessened the likelihood of good statistical correlation.

An alternative explanation, however, is that another factor is involved-an alteration in the absorption or utilization of ascorbic acid after vagotomy. It is striking that, in spite of the return to a full normal diet, the improvement in nutritional status is small, and that even those whose leucocyte ascorbic acid levels were converted to normal remain at the lower limit of normality. The absorption of ascorbic acid is known to be impaired by achlorhydria (Alt, Chinn, and Farmer, 1939), and it has been suggested that the therapeutic hypochlorhydria induced by vagotomy might result in malabsorption of ascorbic acid (Cohen and Duncan, 1967). In this study the reduction in peak half-hour output of acid was taken as an index of reduced gastric acidity, and there was a good negative correlation between this and the postoperative levels of leucocyte ascorbic acid. This finding lends weight to the argument that the hypochlorhydria induced by vagotomy was responsible for the failure of the ascorbic acid nutritional status to improve as much as might have been expected.

Animal experiments have shown that ascorbic acid is essential for the formation of mature collagen in healing wounds (Robertson and Schwartz, 1953), and there is a high incidence of poor ascorbic acid nutrition in patients suffering from wound dehiscence (Crandon et al., 1958). It is evident, then, that poor ascorbic acid nutrition represents a hazard to patients undergoing surgery.

From our findings one might postulate that the accepted minimum intake of $30 \mathrm{mg} /$ day for normal subjects is insufficient for patients suffering from peptic ulcer, even after surgical treatment. It would seem to be a wise precaution routinely to administer ascorbic acid supplements not only to peptic ulcer patients before operation but to any patient undergoing surgery on whom a vagotomy has previously been performed.

We are grateful to Professor A. W. Kay for permission to study patients under his care, and for advice in the preparation of this paper.

\section{References}

Alt, H. L., Chinn, H., and Farmer, C. J. (1939). American fournal of Medical Science, 197, 229.

Archer, H. E., and Graham, G. (1936). Lancet, 2, 364.

Bartley, W., Krebs, H. A., and O'Brien, J. R. P. (1953). Medical Research Council. Special Report Series No. 280.

Cohen, M. M. (1967). British Medical fournal, 2, 243.

Cohen, M. M., and Duncan, A. M. (1967). British Medical fournal, 4, 516.

Cox A. G., Bond, M. R., Podmore, D. A., and Rose, D. P. (1964). British Medical fournal 1, 465.

Crandon, J. H., et al. (1958). New England fournal of Medicine 258, 105.

Denson, K. W. and Bowers, E. F. (1961). Clinical Science, 21, 157.

Gibson, S. I. M., Moore, F. M. L., and Goldberg, A. (1966). British Medical Fournal, 1,1152 .

Harris, L. J., Abbasy, M. A., Yudkin, J., and Kelly, S. (1936). Lancet, 1, 1488.

Hollander, F. (1946). Gastroenterology, 7, 607.

Lazarus, S. (1937). British Medical fournal, 2, 1011.

McCance, R. A., and Widdowson, E. M. (1960) Medical Research Council. Special Report Series, No. 297.

Multicentre Study (1967). Lancet, 1, 291.

Platt, R. (1936). Lancet, 2, 366.

Portnoy, B., and Wilkinson, J. F. (1938). British Medical fournal, 1, 554.

Robertson, W. van B., and Schwartz, B. (1953). Fournal of Biological Chemistry, 201, 689.

\title{
Vaginal Delivery under Caudal Analgesia after Caesarean Section and other Major Uterine Surgery
}

\author{
FERGUS P. MEEHAN, ARVIND S. MOOLGAOKER, JOHN STALLWORTHY
}

British Medical fournal, 1972, 2, 740-742

\section{Summary}

In the absence of a recurring indication for caesarean section vaginal delivery in subsequent pregnancy is a "trial of scar," with potentially serious implications for mother and baby. Labour under caudal analgesia was carefully supervised for 75 women with a surgically scarred uterus-due to lower segment section in 72 , abdominal hysterotomy in one, and transcavity myomectomy in two. Every caesarean scar was assessed digitally during labour and every uterus was examined after delivery. Caudal analgesia provided a painless labour and delivery and made scar assessment easy. Controlled intravenous Syntocinon infusion was given to

\footnotetext{
Nuffield Department of Obstetrics and Gynaecology, University of Oxford, Oxford

FERGUS P. MEEHAN, M.A.o., M.R.C.o.G., Lecturer (Present appointment : Consultant Obstetrician and Gynaecologist, Regional Hospital and University of Galway, Ireland)

ARVIND S. MOOLGÄOKER, M.D., Lecturer (Present appointment: Consultant Gynaecologist and Obstetrician, Basingstoke District Hospital, Basingstoke, Hants.

JOHN STALLWORTHY, F.R.c.s., F.R.C.o.G., Professor
}

25 patients. One scar dehiscence occurred early in labour and one in the second stage. Seventy mothers had 71 vaginal deliveries with one pair of twins and one breech. There was one stillbirth and no neonatal death. There were five repeat sections.

\section{Introduction}

Craigin's (1916) old dictum, "once a caesarean, always a caesarean," has been abandoned and should be replaced by "once a caesarean, always a hospital delivery." His statement referred to classical section, but has since been interpreted by many to include the lower segment operation. When no recurring indication exists and the vertex presents, vaginal delivery should be anticipated. That this is not universally accepted is evident from the fact that in New York City in 1964 47\% of sections were repeat operations (Douglas, 1967). A common and more conservative approach is for patients in a subsequent pregnancy to have a trial of labour. We prefer the term "trial of scar" while admitting that a trial of uterine performance is also involved. We believe that carefully supervised caudal analgesia increases the prospect of success for the reasons which follow.

It makes it possible to assess the lower segment scar from the time the cervix is effaced and two fingerbreadths dilated (see 
Fig.). Scar integrity is no longer a matter of conjecture. A fine ridge or furrow is usually palpable along the line of the scar and its deficiency is easily felt. The scar may be represented by a concentric restriction ring involving almost the whole circumference of the lower st gment at the level of the scar. The presenting part can remain perched on this ring until effacement is complete and the cervix is three to four fingerbreadths dilated. In some cases the lower segment feels completely normal. A gentle examination of this kind is possible in a co-operative patient without regional analgesia, but is facilitated by it, and can be performed under circumstances which would make it otherwise impossible without a general anaesthetic. Digital assessment of the uterine scar is a simple, but important, advance in the safe management of these patients and should be performed with the patient in the lithotomy position. It was

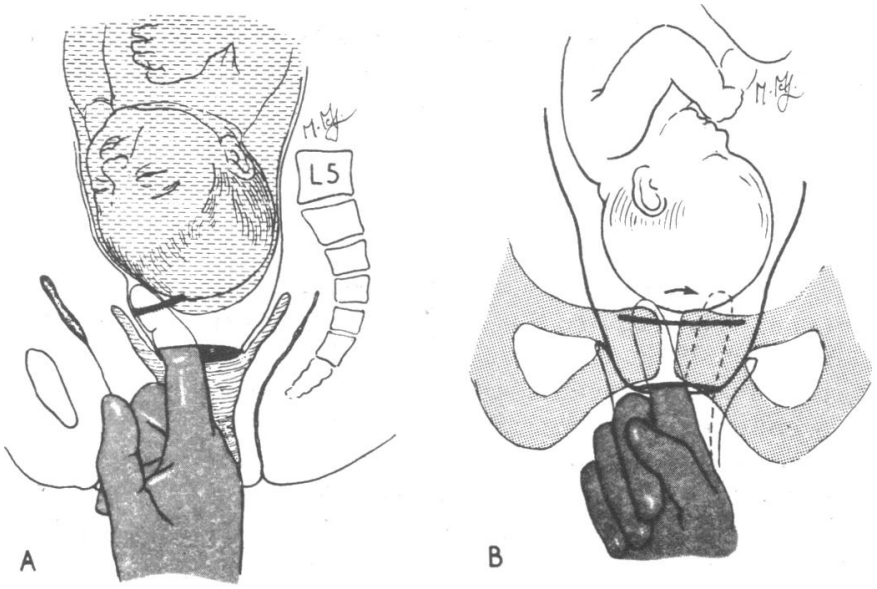

A. Antenatal digital assessment of lower segment scar. Lateral view. B. Intrapartum digital assessment of lower segment scar. Anteroposterior view.

demonstrated by one of us (Moolgaoker, 1970) and we have used it extensively, found it valuable, and have widened its application to include suitable patients in late pregnancy.

A further great advantage of caudal analgesia for these patients is that they can be offered a painless labour and delivery and given the opportunity of participating actively in the birth of their infants without fear. This is in contrast to what happens with an elective caesarean section.

Syntocinon is used judiciously if required, despite the presence of a uterine scar. O'Driscoll et al. (1970) emphasized that they were dealing with primigravid patients in advocating Syntocinon to accelerate labour. Uterine rupture due to oxytocin is rare in the primigravida, but numerous reports-for example, Ferguson et al. (1952)-cite oxytocin as responsible for uterine rupture in the multigravida. It is not surprising that objection has been raised to the use of Syntocinon in the patient with a lower segment scar, but we believe that it can be administered safely in carefully regulated and supervised doses, sufficient to produce a physiological response and simulate normal labour. The doctor remains in close attendance throughout labour.

\section{Patients and Methods}

In many of our patients caudal was the only analgesia used throughout labour. The obstetrician administers the anaesthetic, using the technique described by Meehan (1969) and latterly incorporating his further modifications (Meehan, 1972). These have secured greater general overall success and a personal success rate by one of us (F.P.M.) of $97.7 \%$ in more than 600 obstetric patients. We have found bupivacaine $0.5 \%$ in $1: 200,000$ adrenaline in a dose of $20 \mathrm{ml}$ to be the most effective local anaesthetic agent in securing complete analgesia, not only for labour pains but also for operative intervention. As the average duration of each $20-\mathrm{ml}$ dose is three hours and tachyphylaxis is not apparent, the overall quantity of local anaesthetic used is less than that required with other agents tried. When analgesia was complete a vaginal examination was made and the state of the scar noted.

Great emphasis is laid from time to time on the importance of pain as a symptom of scar rupture. Caudal analgesia abolishes this sign, but the pulse rate and blood pressure recordings are more important for the patient's safety. A silent scar dehiscence is not rare either in late pregnancy or in labour, may cause no maternal or fetal distress, and may be found unexpectedly either if the abdomen is opened or the uterus is explored during or after the third stage of labour. If the rupture causes bleeding, either internal or external, the earliest sign may be a rise in pulse rate followed by a drop in blood pressure. With extraperitoneal haemorrhage clinical deterioration may be out of proportion to the volume of blood lost from the circulation. Hence the importance of frequent pulse and pressure recordings, which should be continuous when monitoring facilities exist.

Many patients with a history of caesarean section will complain of tenderness over the lower abdomen in the antenatal period or during labour, but when examined at section, or after delivery, will have intact scars. We do not consider, therefore, that the abolition of pain or tenderness contraindicates the use of regional analgesia as its advantages far outweigh this single objection if supervision is adequate. But we emphasize the importance of assessing the scar by vaginal examination, repeated if necessary during labour, coupled with regular shortterm recordings of the maternal pulse and blood pressure. Continuous fetal monitoring provides an added safeguard which we have found most helpful.

We favour forceps delivery for these patients as soon as the obstetric situation is favourable. With successful caudal block no further analgesia is required either for this operation or for the mandatory examination of the scar after the third stage. Prolongation of the second stage should be avoided as this can lead to uterine rupture even without a pre-existing uterine scar. Stimulation by intravenous oxytoxic substances increases this risk.

\section{Results}

Caudal analgesia was completely successful in $71(95 \%)$ of the 75 patients. There were four failures-three had a pudendal block for forceps delivery and the fourth had a spontaneous normal delivery with the aid of gas and oxygen. Anaesthesia and analgesia used for delivery were: caudal anaesthesia in 65, general anaesthesia in 6, pudendal block (for failed caudal) in 3, and gas and $\mathrm{O}_{2}$ (for failed caudal) in 1 . Of the 71 patients in whom caudal analgesia was completely successful, 65 were delivered vaginally with no substitution analgesia, five had a repeat lower segment caesarean section under general anaesthesia, and one was prepared for abdominal delivery, but on vaginal examination it was felt that vaginal delivery could be performed safely. A live infant with an Apgar score of 7 at birth was delivered after a forceps rotation and extraction.

Section was repeated because of failure to progress in three patients, cephalopelvic disproportion in one patient, and in the fifth because scar dehiscence was found at vaginal examination during labour.

Dilatation of the cervix varied at the time caudal block was instituted: in 25 it was two to three fingerbreadths, in 28 more than three fingerbreadths, in 1 half dilated, in 8 three-quarters dilated, and in 13 fully dilated. We now administer caudal analgesia when the patient first becomes distressed and requires sedation. The cervix of 13 patients was fully dilated when analgesia was instituted and so the single shot technique was used. This procedure is particularly valuable. when rotation forceps delivery is necessary.

The method of delivery is shown in Table I and, as expected, the forceps rate is high. Thirty-six of the 70 vaginal deliveries 
required rotation of the fetal head and forceps extraction. With one exception, all infants had an Apgar score of 5 or more one minute after delivery (Table II) and a score of 8-10 at five minutes. The exception was a stillbirth. The fetal heart stopped early in the first stage of labour and in retrospect this death was avoidable. The cord was three times tightly around the neck. Continuous fetal monitoring, which is now the practice, might have saved this infant by indicating the need for emergency section. There was no neonatal death.

TABLE I-Mode of Delivery

Spontaneous vaginal delivery Lift-out forceps

Mid-cavity forceps

Manual rotation and forceps

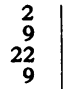

Forceps rotation Ventouse .

Breech

Repeat lower segment caesarean section

TABLE II-Apgar Scoring of Infant after Delivery

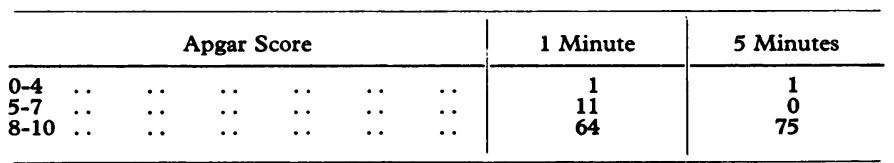

Spontaneous onset of labour occurred in 38 patients and the remainder were induced medically or surgically-artificial rupture of membranes in 12, spontaneous rupture of membranes and Syntocinon in 2, artificial rupture of membranes and Syntocinon in 5, and artificial rupture of membranes and Syntocinon during labour in 18. In some instances both methods were used. Twenty-five patients received Syntocinon in doses sufficient to simulate normal labour. Two patients had scar dehiscence, one was detected unexpectedly intrapartum by vaginal examination, and at section a live infant was delivered. The second rupture was found after delivery of a live infant and was repaired at laparotomy. Neither patient had received Syntocinon.

\section{Discussion}

We consider that elective repeat caesarean section is meddlesome obstetrics unless there is a recurring indication. Carefully supervised caudal analgesia for vaginal delivery after lower segment caesarean section, hysterotomy, or transcavity myomectomy is a safe procedure and should be practised more widely. We are unaware of any reports on the use of caudal analgesia in the management of labour after caesarean section. Danger of concealing pain or tenderness as an indication of possible scar rupture is obvious, but digital assessment of the scar, as described above, and careful monitoring of both mother and fetus during labour more than compensate for this. As a guiding rule the best way to ensure vaginal delivery is to await the spontaneous onset of labour, but either fetal or maternal interest may necessitate termination of pregnancy by section or induction. Objections have been raised to using Syntocinon in this type of case, but it seems illogical to withhold therapeutic doses of a drug which can be beneficial subject to careful monitoring.

General anaesthesia was used for five patients who required caesarean section. We have performed section under caudal analgesia, but with the technique used in this series the level of anaesthesia would be inadequate for upper abdominal exploration. A therapeutic dose of $30 \mathrm{ml}$ of local anaesthetic agent would be required. It is widely accepted that if caudal analgesia is instituted before labour is well established it may interfere with its progress (Lyons and Hansen, 1944; Mylks, 1945; Mines and Holroyd, 1946). Experience has shown that if analgesia is induced when the patient first requires sedation contractions may be abolished for 10 to 15 minutes but they return with the frequency and intensity of normal labour. In incoordinate uterine action caudal analgesia has resulted in normal labour, especially when coupled with Syntocinon infusion.

We agree with Scudamore and Yates (1966) that pudendal block provides inadequate analgesia for vaginal manipulations whereas caudal analgesia is ideal for manual or forceps rotation. The relaxation of pelvic musculature makes both the rotation and the delivery simpler and safer and reduces compression on the fetal skull. In many instances episiotomy was unnecessary because of the relaxation obtained.

In the patient whose scar was found ruptured after delivery it was felt that this occurred late in the first stage or during delivery because it was intact on two separate occasions during labour. The infant was unaffected and the tear was repaired one hour later.

\section{Conclusion}

Nature is not always a good obstetrician. While it is true to say that many have believed that labour is a physiological process and nature should take its course, the patient may suffer as a result. Part of the art of obstetrics consists in recognizing abnormalities early and taking the necessary action. Many obstetricians have become somewhat complacent to the widespread use of general anaesthesia in obstetric practice and have tended to use it more and more for operative delivery. The recent maternal mortality reports for England and Wales have shown the danger of this practice, and general anaesthesia may become the major single cause of maternal death. Maternal and fetal mortality rates have been reduced but there is more obstetric interference and more patients are anaesthetized. Having ignored many warnings, such as those of Jeffcoate (1953) and Tompkinson (1957), emphasizing the dangers of general anaesthesia to both mother and baby, obstetricians must re-examine their views and practice, and give regional analgesia its rightful place in obstetrics. Elective caesarean section without adequate justification usually subjects the patient to the dual insult of unnecessary general anaesthesia and unnecessary surgery.

We gratefully acknowledge the invaluable help given by Miss Janet Johnson, research assistant, in the analysis of data and preparation of Tables, and our consultant colleagues for their co-operation in this study.

\section{References}

Craigin, E. B. (1916). New York Medical fournal, 1, 104

Douglas, G. R. (1967). Advances in Obstetrics and Gynaecology, ed. S. L. Marcus and C. C. Marcus, p. 276. Baltimore, Williams and Wilkins. Ferguson, J. H., Schneider, G. T., and Miller, H. K. (1952). New England fournal of Medicine, 246, 649 .

Jeffcoate, T. N. A. (1953). British Medical fournal, 2, 951.

Jeffcoate, T. N. A. (1953). British Medical fournal, 2, 951 . and Gynecology, 47, 105.

Meehan, F. P. (1969). Proceedings of the Royal Society of Medicine, 62, 185. Meehan, F. P. (1972). Oxford Medical School Gazette, 24, 36.

Mines, J. L., III, and Holroyd, E. A. (1946). Fournal of the American Obstetric Association, 45, 194.

Moolgaoker, A. S. (1970). Fournal of Obstetrics and Gynaecology of the British Commonwealth, 77, 1077.

Mylks, G. W., jun. (1945). Canadian Medical Association Fournal, 52, 169.

O'Driscoll, K., Jackson, R. J. A., and Gallagher, J. T. (1970). Fournal of Obstetrics and Gynaecology of the British Commonwealth, 77, 385.

Scudamore, J. H., and Yates, M. J. (1966). Lancet, 1, 23.

Tompkinson, J. S. (1957). Proceedings of the Royal Society of Medicine, 50, 552. 